\title{
51
}

\section{E-democracy and the Scottish Parliament}

\author{
Lesley Beddie, Ann Macintosh and Anna Malina \\ The Scottish Parliament, Edinburgh, UK. And \\ International Teledemocracy Centre, Napier University, 219 Colinton Road, Edinburgh, UK
}

\begin{abstract}
This paper focuses on the introduction and use of information and communication technology (ICT) in the new Scottish Parliament to enhance Scottish citizens' understanding of the governance of Scotland and to encourage them to participate in the democratic decision making of Scotland. The primary focus is the use of the World Wide Web as a vehicle both for dissemination of information and for interaction with the Parliament.

In particular, the paper concentrates on one aspect of use of the Web, i.e. that of electronic petitions. The Scottish Parliament actively promotes petitions as a way in which the public can effectively lobby the Parliament, and has established a Public Petitions Committee which enables the public to submit written or electronic petitions. Essentially, the paper assesses the value of electronic petitioning in the Scottish Parliament.
\end{abstract}

\section{INTRODUCTION}

This paper focuses on the introduction and use of information and communication technology in the new Scottish Parliament to enhance Scottish citizens' understanding of the governance of Scotland and to encourage them to participate in the democratic decision making of Scotland. Budge (1996) argues that democratic political participation must involve both the means to be informed and the mechanisms to take part in democratic decision making. In this paper we demonstrate how the Scottish Parliament is using internet-based technology to address citizen participation through these joint perspectives of informing and participating. The primary focus is the use of the World Wide Web as a vehicle both for dissemination of information and for interaction with the Parliament. 
In July 1999 the Scottish Parliament was officially opened. This gave devolved power for specific areas of government from the Westminster Parliament in London to a new Scottish Parliament based in Edinburgh. One of the main documents setting out how the new Parliament should work was The Consultative Steering Group document (The Scottish Office, 1998a). This stated that the Scottish Parliament should aspire to use all forms of information and communication technology "innovatively and appropriately" to support its three principles of openness, accessibility and participation.

Prior to the official opening of the Parliament, a working group on the use of information and communication technology was established, which made important recommendations on the future of technology in the new Parliament. This group, the 'ICT Expert Panel', reported directly to the Consultative Steering Group and its recommendations helped to ensure that technology was a fully integrated component of its business processes rather than a later add-on. The report (1998b) of the Expert Panel was published separately from that of the Consultative Steering Group's Report as it was lengthy and also generally recognised as containing information worthy of a separate document.

The remit of the Expert Panel was to provide advice on how the Parliament might use technology to:

- promote internal efficiency and innovative ways of working;

- provide information about its proceedings and its work to the widest possible audience in the most accessible way;

- make it as easy as possible for the Parliament and individual MSPs (Members of the Scottish Parliament) to exchange information with external organisations and the public;

- encourage democratic participation and involvement.

Membership of this panel comprised a cross section of Scottish people, including both ICT experts and potential end-users of the technology.

The work of the Panel was to extend thinking on the value and use of ICT beyond just the operation of Parliamentary business and into information provision and accessibility which might in turn create and use new services. In so doing, the Panel split into sub-groups, and the report from one of those groups, the sub-group on Democratic Participation, was reported in both the final Consultative Steering Group report and the Expert Panel report. It went beyond what might be termed as core business requirements of the Parliament and gave proposals for how ICT might extend these and add value in addressing public access to, and interactions with, the democratic process. Section 2 introduces the technology provided by the Scottish Parliament to enable Scottish citizens to be better informed about the governance of Scotland and the workings of the Parliament in general.

In August 1999, Napier University established the International Teledemocracy Centre in partnership with BT Scotland. Its remit is to develop innovative edemocracy systems that have the potential to strengthen public understanding and 
participation in the democratic decision-making process. To achieve this, the Centre is undertaking research into electronic democracy and developing an e-democracy toolkit to act as a show-case of e-democracy applications. The aim is to demonstrate the potential benefits of the use of technology in supporting the democratic process. The Centre's web site is at http://www.teledemocracy.org. Section 3 describes how the Centre, working with the Scottish Parliament, is starting to introduce edemocracy tools into the democratic processes of the Parliament through the introduction of an e-petitioning tool to facilitate the electronic lobbying of the Parliament. The section describes how the requirements of the citizen wishing to petition the Parliament electronically are met whilst also ensuring the Parliament has confidence in the integrity of such an electronic petitioning system.

\section{THE SCOTTISH PARLIAMENT'S USE OF THE WEB}

The Scottish Parliament web site is at www.scottish.parliament.uk. All documents and debates relating to the business of the Parliament are available online. It was one of the earliest recommendations of the ICT Expert Panel, and one that was acted upon very quickly, that the Parliament must use the Web as an information source and shop window for its work. This was to include not only business papers and reports, but also general information about, for example, the education centre and progress on the new Parliament building.

The web site is, effectively, the premier publishing medium for the Parliament although, for accessibility reasons, it is obviously not the only medium in use. The web site publishes the Official Report of the Parliament's meetings in the Chamber by $7 \mathrm{am}$ on the following day, and Committee Reports as soon as possible and generally within 3 days of the meeting. The publication deadlines for the latter reports have been foreshortened from those first defined in 1999 in recognition of the fact that the committee papers are of great interest and the demand is high. In addition, and as a further step towards openness, committee agendas and papers are published in advance where at all possible. The web site is constantly being added to and access enhanced. It is presently going through a major redesign exercise even though it is less than 2 years old, in order to ensure that it meets the needs of its audience. The figure below shows the main page for the Scottish Parliament. 


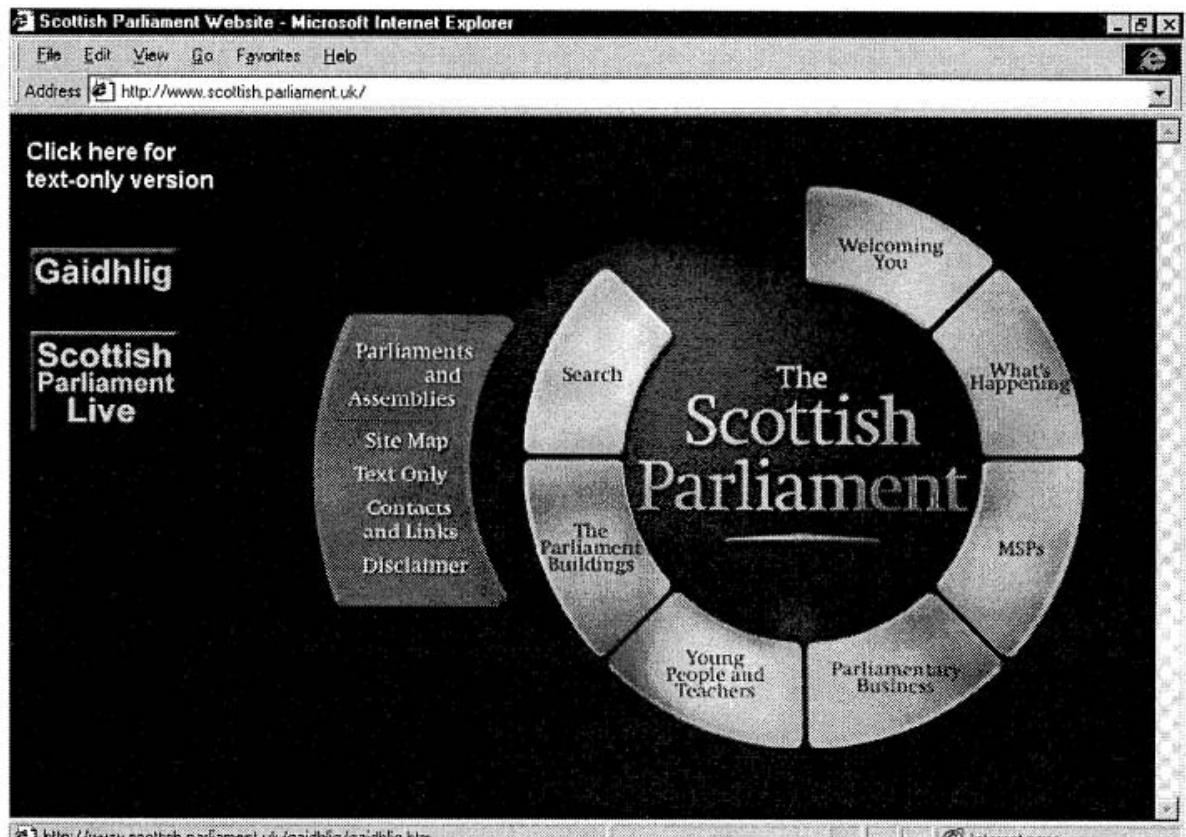

d] hitp://unzw scottosh paliament uk/gaidhlig/gaidhlightm

Rinternet zone

Figure 1. Scottish Parliament web-site

The more interactive aspects of the web service include the submission of electronic petitions (see section 3), the publication of the email addresses of all MSPs, their biographies and links to personal web pages, alongside phone and fax numbers and correspondence addresses. Email addresses for clerks to committees and for offices within the Parliament are also published. The recent webcasting service broadcasts Chamber and Committee meetings live across the web so that organisations and individuals can listen in and watch items of particular importance to them. The service also includes access to the (small but growing) audio-visual archive of webcasts, and relevant papers for the committee meetings. This service is new, but the 12 month plan is to extend it to give better access to the audio-visual archive, to webcast over broadband, and to use it as a vehicle to enable committees to receive feedback and consult through the webcast.

The Parliament is charged with providing information to, and receiving information and opinions from, all Scottish organisations, groups or citizens, and it must do so using all the channels of communication which are available and required. Paper, telephones, TV, ICT are all channels which are used. However, the internet is the main channel for the provision of innovative, rather than simply automated, services to and from the Parliament, and therein lies its value and the reason why it will continue to be part of its core provision. 


\section{ELECTRONIC PETITIONING}

\subsection{Petitioning and the Scottish Parliament}

A petition is a formal request from citizens to a parliament. In many countries around the world citizens have used petitions for a long time to make their feelings known about issues that concern them. The format of petitions and the way petitions are submitted and subsequently processed by parliaments varies greatly. This variation may be demonstrated by considering petitions to the UK parliament in Westminster and to the Scottish Parliament. The Westminster Parliament publishes a comprehensive set of rules on how to submit a petition. For the purpose of this paper, the important ones relate to the format and the submission procedure. The page on which the petition appears must be hand-written and every petition must be specifically and respectfully addressed to the House of Commons. The petition must have hand-written signatures along with the addresses of the signatories. Only Members of the House of Commons can present petitions. They can be submitted (except on Fridays) immediately before the half hour adjournment debate at the end of each day's business or they can be placed in a large green bag hooked onto the back of the Speaker's Chair. Although this appears a somewhat elaborate procedure, little actually happens to the petition once it is submitted. Many Members term the green bag 'the black hole for petitions.' The fact that only a Member can submit a petition also goes against petitions being an effective lobbying tool for the citizen.

The Scottish Parliament actively promotes petitions as a means by which the public can effectively lobby parliament. On the issue of petitions, the Consultative Steering Group stated:

"It is important to enable groups and individuals to influence the Parliament's agenda. We looked at a number of models in other Parliaments for handling petitions and concluded that the best of these encouraged petitions; had clear and simple rules as to form and content; and specified clear expectations of how petitions would be handled."

To achieve this the Scottish Parliament established a dedicated Petitions Committee. Figure 2 below shows the home page for the Public petitions Committee (PPC). 


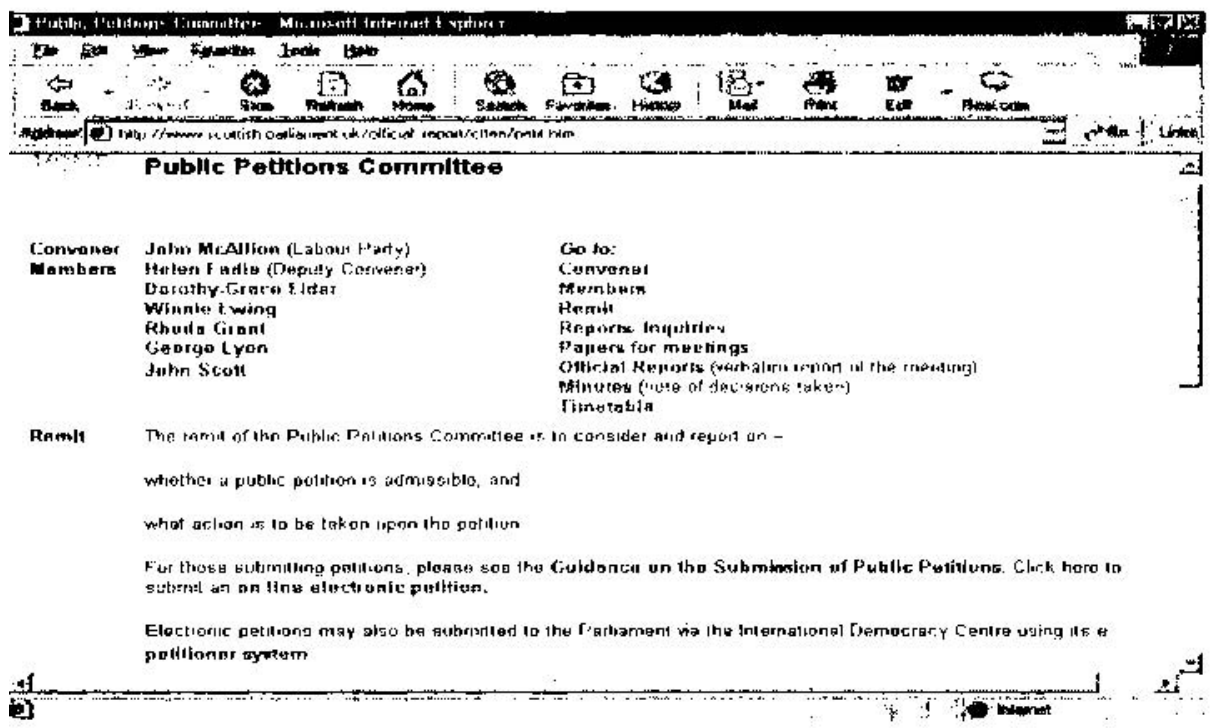

Figure 2. Public Petitions Committee web-site

The remit of the PPC is to consider and report on whether a public petition is admissible and what action is to be taken on the petition. The PPC considers each admissible petition and makes a decision on the action to be taken in each case. From July 1999 to 7 November 2000 the PPC had received and dealt with approximately 300 petitions. An individual, a corporate body, an interest group, or any other association may submit a petition. As regards format, petitions must be in proper form that is determined by the PPC from time to time. In December 1999, the Scottish Parliament agreed to allow an internet-based petition from the ITC's web site sponsored by the World Wildwide Fund for Nature (WWF) to be the first electronic petition to collect names and addresses over the internet. The Parliament subsequently agreed to allow groups and individuals to submit petitions using the Teledemocracy Centre's internet petitioning system for a trial period.

The report of the meeting of the Public Petitions Committee on $14^{\text {th }}$ March, 2000 to trial internet petitions can be found at: http://www.scottish.parliament.uk/official report/cttee/petit-00/pumop0314.htm.

The special arrangement between Teledemocracy Centre and the Scottish Parliament is allowing both parties to start to evaluate the use and civic impact of electronic petitioning in Scotland.

\subsection{The e-petitioner Tool}

The e-petitioner tool, at www.e-petitioner.org.uk, has the functionality to create a petition; to view/sign a petition; to add background information, to join an 
integrated discussion forum; and to submit a petition. Figure 3 shows a petition screen with the text of a recent electronic petition on digital inclusion.

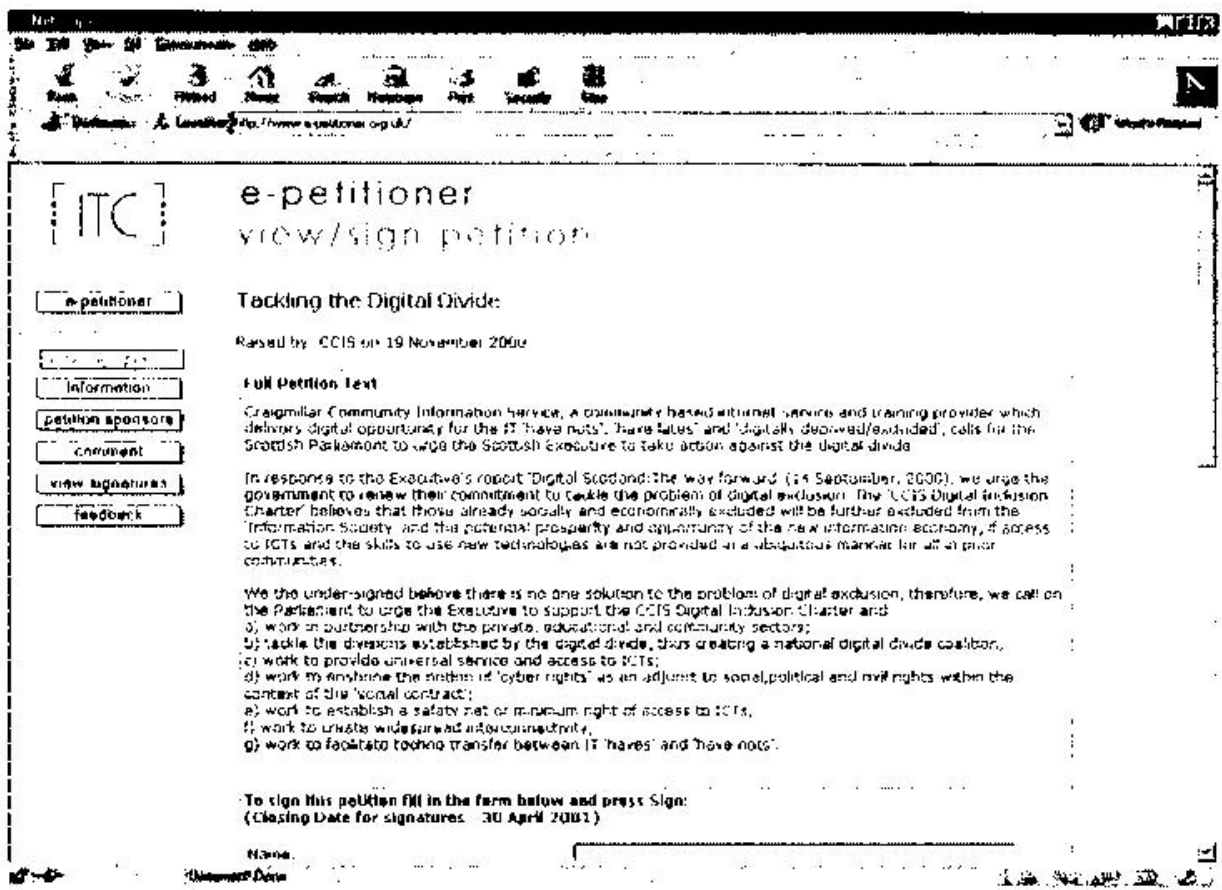

Figure 3. e-petition text: 'Tackling the Digital Divide'

Macintosh et al (2001) describe the critical issues to be considered in the design of e-democracy systems. In designing the e-petitioning system it was necessary to consider how technology could be used most effectively to support the five key enabling criteria of accessibility, usability, security, transparency and trust. However the very nature of governance and the fact that government cannot choose its customers means that, in the design of e-democracy systems, these issues become complex.

With regard to e-petitioner it was important to provide access for as many people as possible. With this in mind, the system does not use frames or contain large graphics files. It was important that local community centres running slower machines could easily access the system. The unequal technical capabilities of citizens demanded that e-petitioner was simple to use. It was also important that features that might make the system difficult for the partially sighted to use were excluded.

In some respects, accessibility and security can be conflicting design issues, however, as petitions to the Scottish Parliament are not legally binding, "external" 
security measures that might have run counter to good accessibility were not required. Therefore, a detailed user-registration process was excluded. Instead the system runs "internal" security checking on the names signing the petition. However there still remains the question of how much checking of names and addresses is necessary for electronic petitions? This is an important question to address. It would be easy to say that it should match the level currently available for paper-based petitions but that then raises the issue of what level of security checking is actually used for paper-based names and addresses other than manually reading the often illegible handwriting. On the other hand there is always the temptation to say that everything must be checked thoroughly, which is the case for electronic voting, but not necessarily for names and addresses on petitions. The "internal" checking is accomplished by e-petitioner giving each name and address a "confidence" rating. The actual rating depends on a number of factors, for example, Internet Provider (IP) address and how many times the same IP address has been used to sign the petition. These confidence ratings are closely examined prior to submission of the petition to check for any irregularities. The system also automatically removes any duplicate names and addresses.

It was important to ensure that the petitioning process was as transparent as possible. However, in some respects usability and transparency can be conflicting design issues. There is a need to ensure straightforward navigation through the system, but there is also a need to ensure that the participation process and relevant information underlying the petitions are open to everyone Transparency was achieved through three mechanisms. Firstly, by providing background information on the petition, ensuring that people can be adequately informed about the petition issues and therefore can better decide whether to support the petition or not. Secondly, by incorporating an integrated discussion forum so that people who do not want to support the petition or others who feel they have further evidence in support of the petition can add their own statements on-line. Thirdly, e-petitioner has a feedback facility such that the petition sponsor can inform everyone on the progress of the petition once it has been submitted to the Scottish Parliament.

Given the above requirements, the detailed functionality of E-Petitioner is:

- the petition sponsor can create the petition, giving the text of the petition and the address of the petitioner to which all communications concerning the petition should be sent;

- the petition sponsor can add on-line background information to provide rationale for the petition and to better inform those reading the petition;

- persons wishing to support the petition can add their names and

- addresses on-line, see figure 4;

- additionally persons wishing to raise any issues about the petition can do so online through the integrated, on-line discussion forum;

- the discussion forum is available for anyone to read or send comments to

- whether they support the petition or not; 
- persons wishing to add their names or enter the discussion do not require an email account, they can do so from any internet access point - public kiosk, cyber café, community centre, home, etc;

- with regard to petition statistics, the number of persons supporting the petition is automatically updated along with the names and areas/countries, this information is available for anyone to view;

- full names and addresses are filed for use with, and only with, the petition (unless consent for other use is given by the person adding their name and address) ensuring data protection requirements are adhered to;

- duplicate names and addresses are automatically removed;

- checking names and addresses is performed prior to submission of the petition by the system allocating a "confidence rating" to each name;

- the petitioner can submit the petition with names and addresses electronically and/or can produce a paper version of the petition for submission;

- the format for the submitted petition adheres to the guidelines of the Scottish Parliament.

To be able to quickly demonstrate and try out the e-petitioner functionality the first version of the system was developed using cgi scripts and html files. It was available from both Explorer and Netscape browsers. Once e-petitioner was accepted for trial use by the Scottish Parliament, the system was updated to reflect feedback from users and the Parliament. The current version of e-petitioner is implemented in using Microsoft SQL and ASP. There are links to the electronic petitioning system from the Scottish Parliament's web site and links from the Teledemocracy Centre's web site to the Parliament's guidelines for petitions. 


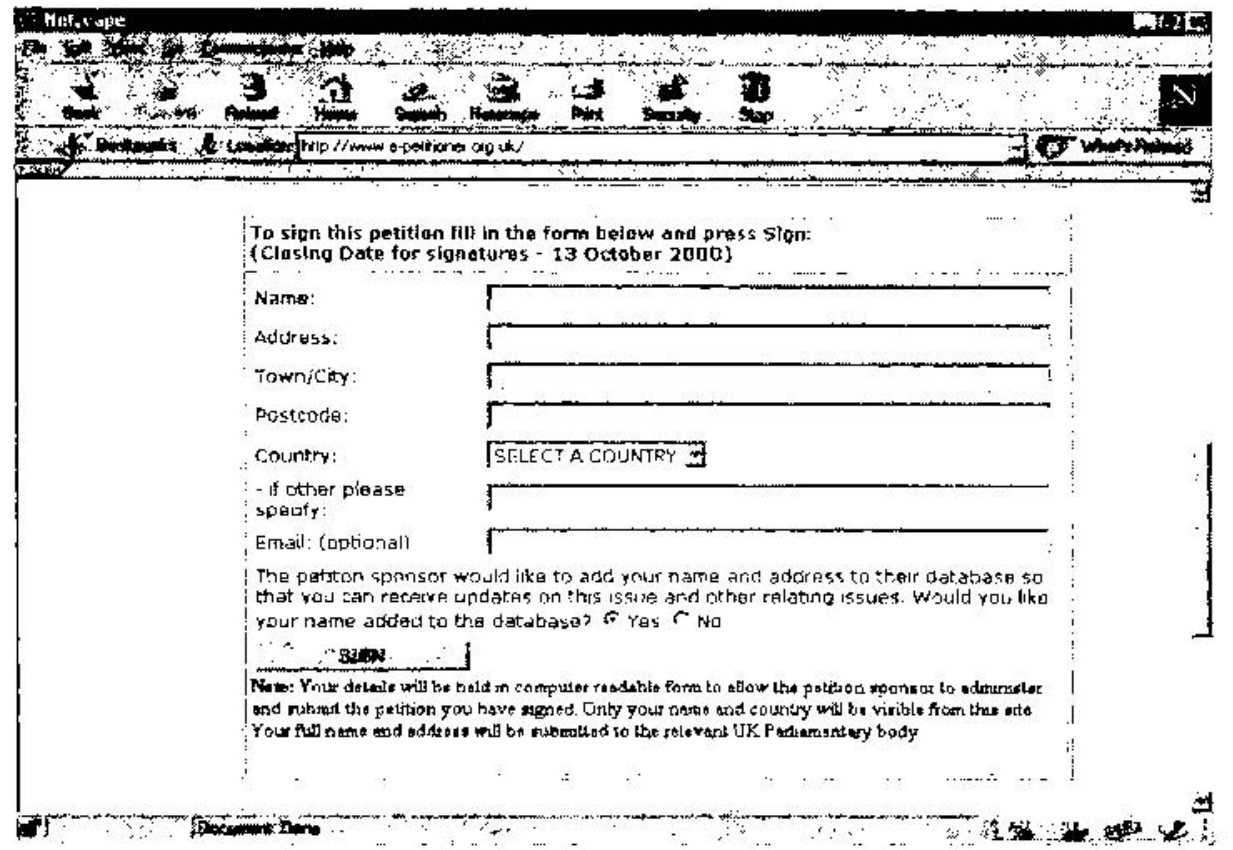

Figure 4. e-petitioner on-line form

The first e-petitions are very much pilot electronic petitions to the Scottish Parliament, and it is therefore difficult to draw many conclusions from them. However, it was originally thought that electronic petitioning might let the internet run wild and thousands of frivolous names and addresses would be collected. Our initial evaluation has shown this is not the case. Indeed, the opposite could be argued. Instead of a pen being thrust into the hand of the would-be petitioner with a request to "sign here", the petitioner needs to be much more committed to the petition cause. They have to: boot up their PCs, log onto the internet, search the net for the site and then examine and reflect on information before deciding to sign. In this way the names and addresses being gathered could be considered a more realistic representation of those supporting the petition cause. The Teledemocracy Centre has received research funding from the Joseph Rowntree Charitable Trust to undertake a detailed evaluation of the impact of e-petitioner on participation levels.

\section{CONCLUSIONS}

The use of technology by the Scottish Parliament to support democracy in Scotland has been described. In particular, the web is a major communication channel and will continue to be exploited and employed by the Parliament for the delivery of services. Already the Scottish Parliament is at the forefront of the use of 
webcasting in Parliaments to provide wider access to its committee and plenary meetings.

Groups or individuals may submit petitions to the Parliament, electronically or on paper. The admissibility of electronic petitions has enabled the Parliament to work with the ITC to learn more about the process by which petitions are created and delivered, and to gather information about the issue, the process and the petitioners, which may be of great value to the committees in better assessing public feelings and wishes. While many challenges remain, the design of e-petitioner has demonstrated already that electronic petitions can be effective. E-petitioning will not necessarily create a large number of frivolous names and addresses as previously feared. Instead, with its unprecedented capability to quickly transcend time, space and place, the new system has allowed petitioners to better inform the wider public about specific issues of concern. E-petitioner's features have also presented new opportunities for people to explore background information, deliberate and reflect on issues before signing a petition and/or commenting on it. Finally, e-petitioner has -at least to some extent -- allowed sponsors to better understand some of the concerns other members of the public have about the particular issues raised.

\section{REFERENCES}

Budge, I. (1996). The new challenge of direct democracy. Cambridge: Polity Press MacIntosh, A., Davenport, E., Malina, A. \& Whyte, A. Technology Driven Inclusive Democracy. In Grönlund, Åke (2001). (ed). Electronic Government: Design, applications and management (in print).

Scottish Parliament (2000). The report of the meeting of the Public Petitions Committee on $14^{\text {th }}$ March, 2000 to trial internet petitions. At URL http://www.scottish.parliament.uk/official_report/cttee/petit-00/pumop0314.htm.

The Scottish Office (1998a). Shaping Scotland's Parliament. Report of the Consultative Steering Group.

The Scottish office (1998b). Final Report of Expert Panel on Information and Communications Technologies for the Scottish Parliament.. The ICT Expert Panel. 